\title{
CERVICAL ADENOCARCINOMA
}

\section{CLINICAL IMPLICATIONS OF THE RISK STRATIFICATION SYSTEM (SILVA SYSTEM)}

Devoto G; Falcon F; García Kamermann F; Alessandria S; Lange J; Torres G; Cardinal L; Tatti S; Bemudez A GYNECOLOGIC ONCOLOGY UNIT, PATHOLOGY DEPARTMENT, BUENOS AIRES UNIVERSITY HOSPITAL. BUENOS AIRES, ARGENTINA.

\section{OBJECTIVE}

To correlate the Silva system with prognosis and outcome.

\section{METHODS}

32 patients with cervical adenocarcinoma were included between 6-90 and 10-16. Median age was 43 years. Median follow-up was 66 months. Slides from surgical specimens were classified by two pathologists. Results were correlated with: tumor size, FIGO staging, site of recurrence, DFS and OS.

\section{RESULTS}

Twelve patients (37\%) had pattern A tumors; all stage I and with no lymph node metastases (LNM) or recurrences.

Pattern B was seen in 13 tumors (41\%); all stage I, LNM was seen in 2 (15\%). One patient had a local recurrence in this group (8\%).

Pattern C was found in 7 cases (22\%), all with LVI. Five $(71 \%)$ showed LNM and recurrences were recorded in 4 (57\%).

Tumor size was: $<2 \mathrm{~cm}$ A: 8 (66\%), B: 2 (15\%), C: 0 $(0 \%)$ and $=0>2 \mathrm{~cm} \mathrm{A:} 4$ (34\%), B: $11(85 \%)$ and C: 7 (100\%).

DFS was: $A=73$ months, $B=76$ months, $C=58$ and the OS was: $A=55$ months, $B=79$ months, $C$ $=62$ months.

One Pattern C tumor presented ovarian involvement. The only 2 distant recurrences were Pattern $\mathrm{C}$ patients.

\begin{tabular}{|c|c|c|c|}
\hline PATTERN & N & LNM & RECURRENCE \\
\hline A & $12(37,5 \%)$ & $0(0 \%)$ & $0(0 \%)$ \\
\hline B & $13(40,62 \%)$ & $2(15,38 \%)$ & $1(7,69 \%)$ \\
\hline C & $7(21,87 \%)$ & $5(71,4 \%)$ & $4(57,14 \%)$ \\
\hline
\end{tabular}

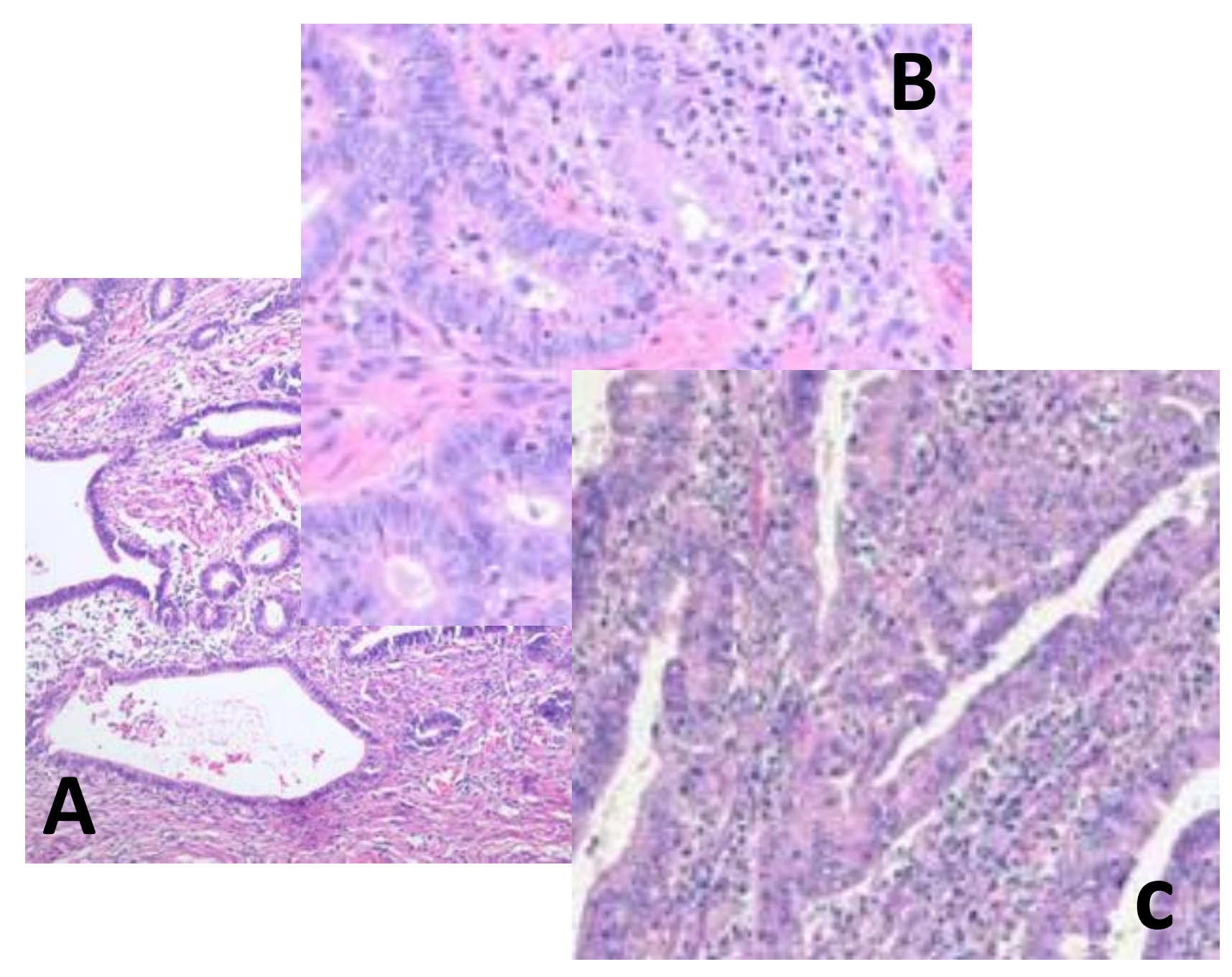

\section{CONCLUSIONS}

There is a relation between FIGO staging, DFS and OS. In our series, Pattern $C$ tumors seem to have higher incidence of nodal involvement and local and distant recurrences. 